\title{
A method for characterizing sarcoma tumour boundary scanned with T2-weighted MRI
}

\author{
Todd L. Richards ${ }^{1}$, J anet F. Eary ${ }^{1}$, Finbarr O'Sullivan ${ }^{2}$, Ernest U. Conrad ${ }^{3}$ \\ 1. Department of Radiology, University of Washington, USA. 2. Department of Statistics, University of College Cork, \\ Ireland. 3. Department of Orthopedics and Sports Medicine, University of Washington Medical Center, USA. \\ Correspondence: Todd Richards. Address: Department of Radiology, Box 357115, University of Washington Medical \\ Center, 1959 NE Pacific, Seattle, WA, 98195, USA. Telephone: 01-206-616-0015. Email: toddr@u.washington.edu
}

Received: June 16, 2011

DOI : $10.5430 /$ jbgc.v1n1p1
Published: December 1, 2011

\section{Abstract}

Objective: Analysis of the tumor boundary could play an important role in increasing the understanding of tumor relationships with normal structures for surgical resection planning and risk assessment for local recurrence in sarcoma. The objective of this paper is to present analytical methods that were developed to characterize the tumor boundary using the signal from T2-weighted MRI in a test set of images from patients with sarcomas.

Methods: The study MRI parameters were compared to histopathological data from the resected tumors. T2-weighted clinical MR scans were acquired from 20 subjects from patients diagnosed with sarcoma. Computer software was developed to characterize the MR intensity of the tumor boundary as function of distance along probing radii.

Results: There were significant differences in the MRI tumor boundary parameters between tumors resected with positive or negative margins. The slope of the T2 signal change at the tumor/normal tissue boundary $(p=0.007)$ and boundary distance $(p=0.001)$ were significantly correlated with tumor margin status.

Conclusions: These data demonstrate that this image analysis algorithm which characterizes the change in MR signal at the tumor boundary could be useful in the clinical evaluation of the tumor. The spatial position of this MR signal slope parameter that correlates with positive tumor margins can be identified precisely while the tumor is still in the body of the patient prior to tumor removal. This boundary analysis method which is different than simple edge detection reports on the tumor-normal tissue interface.

\section{Key words}

Tumor boundary, T2-weighted MRI, MR images

\section{Introduction}

Analysis of the tumor boundary in MR imaging could play an important role in increasing the understanding of tumor relationships with normal structures for surgical resection planning and risk assessment for local recurrence in sarcoma. For most surgical resection planning, the MR images are used to identify the size and extent of tumor, involved structures, and other tissue characteristics qualitatively. However, there is little work that has investigated methods to Published by Sciedu Press 
quantitatively characterize the tumor interface with normal tissues pre-operatively using imaging. Since its initial discovery in the 1970s, there have been several thousand publications showing the utility of T2-weighted MRI for diagnosis and radiological characterization of tumors. This experience is well described in a review of MRI utility in sarcomas by Varma et al. [23]. There are several papers that describe the importance of T2-weighted MRI in clinical sarcoma diagnosis and treatment MR as evidenced by the following 21 publications, many of which performed a radiological/pathological correlation and specifically describe the tumor boundaries and rims [1-6, 8-22]. The boundary changes are likely caused by edema and other processes and are noted in the papers below. For example, Furukawa et al. (2010) used a histopathological examination to reveal that the T2-weighted detectable rim in uterine tumors consisted of fibrous tissue layers and a decrease in free water caused by distortion of myometrial tissue following tumor expansion. In another study by Barile et al. (2002), both T1 and T2-weighted images were used to find an accurate definition of the lesion boundaries to exclude or demonstrate local region invasion. More specific to tumor boundary characterization, investigators have made several other observations. In a more recently published study, Liu et al. used MRI to qualitatively characterize sarcoma tumor boundary/margins [14]. They showed that sarcoma histological grade was related to the tumor margin appearance $(P<0.05)$ : the margin was well defined in $60 \%$ of grade I tumors, and poorly defined in $60 \%$ of grade III tumor. However, analysis of the tumor margin infiltration characteristics was not described beyond noting the presence or absence of a peri-tumoral bright zone, or the presence of a pseudocapsule. Fernebro et al. [7] investigated the correlation of measurements of infiltrative microscopic peripheral growth and MRI tumor appearance. Their results showed that all tumors with diffuse peripheral normal tissue infiltration noted in pre-operative MRI images also showed microscopic infiltration and had prognostic significance [7].

The objective of this paper is to present analytical methods that were developed to characterize the tumor boundary using the signal from T2-weighted MRI in a test set of MRI images from patients with sarcoma. This technique (which characterizes the intensity change at the tumor boundary) goes far beyond tumor edge-detection (which only defines the spatial position of the tumor boundary). T2-weighted MRI was chosen because of the large difference in water mobility characteristics (with its associated difference in T2 relaxation time) between sarcoma and normal surrounding tissue. The study MRI tumor boundary parameters were compared to histopathological data from the resected tumors where the tumor margin status was reported.

\section{Methods}

T2-weighted clinical MR scans were acquired from 20 subjects who were diagnosed with sarcoma. This was a retrospective analysis of scans that were routinely collected as part of the clinical radiological protocol in sarcoma patient evaluation. The scans were acquired on 3 different MR scanner types (9 from General Electric Signa Excite, 6 from Philips Medical Systems and 5 from Siemens). Although other MR scan series were acquired as part of the standard clinical protocol such as T1-weighted series, short-tau inversion recovery (STIR) series, and a pre-post Gadolinium contrast T1-weighted series, the focus of this project was in the use of T2-weighted MR images. This study was approved by the University of Washington Institutional Review Board/Human Subjects Committee and all of the subjects signed a study consent form. The scans used fast-spin echo type pulse sequences, with T2-weighted echo times ranging from 69 to $100 \mathrm{msec}$, repetition times ranging from 3000 to $5000 \mathrm{msec}$, and field of view and scan resolution set to encompass the body part where the tumor was located. Typical spatial matrix for acquisition was 512voxels $\times$ 512 voxels $\times 66$ voxels with dimensions of $0.8 \mathrm{~mm} \times 0.8 \mathrm{~mm} \times 7 \mathrm{~mm}$.

\section{Tumor image analysis algorithm}

The MRI T2-weighted image data set consists of a three-dimensional spatial array of MRI intensity at each of $\mathrm{N}$ tissue volume elements. Measures of tumor boundary characteristics are based on a sampling of the MRI intensity from 90 
constructed sampling rays that stem from a point near the center of the tumor (identified by the radiology oncologist). An anatomical reference location was also identified by the radiology oncologist.

Software was written in fortran to perform the following steps:

a) Read in the 3 dimensional T2-weighted image into a 3 dimensional fortran array

b) Read in a file with $\mathrm{X}, \mathrm{Y}, \mathrm{Z}$ coordinates of tumor center and reference tissue center

c) Determine the mean MR signal and standard deviation of the tumor and reference tissue

Generate 90 radial rays stemming from the user-defined tumor center using the following equation (the radial rays are confined to the same in plane resolution as the T2-weighted image):

$$
\begin{aligned}
& \mathrm{X}(\text { angle, ray length })=\text { cosine }(\text { angle }) * \text { ray length } \\
& \mathrm{Y}(\text { angle, ray length })=\text { sine }(\text { angle }) * \text { ray length }
\end{aligned}
$$

Where $\mathrm{X}$ is the $\mathrm{X}$ (horizontal) cartesian coordinate in the same space as the T2-weighted image, $\mathrm{Y}$ is the $\mathrm{Y}$ (vertical) cartesian coordinate. $\mathrm{X}$ and $\mathrm{Y}$ are functions of the angle and the ray length. The angle is incremented 90 times every 4 degrees for a total of 360 degrees and the ray length is incremented in the nested do loop (a nested do loop is a way to increment through the variables defined above-angle, ray length) every pixel until it reaches the length of the ray (which is set to be large enough to extend from within the tumor to the tumor boundary). This procedure generates 90 rays for analysis and places them in the image matrix space so that they can be used to sample the tumor signal (MRI intensity values from the T2-weighted image) near the boundary. Figure 1 shows an example of the 90 probing rays overlay on a T2-weighted image of a sarcoma. Each of the 90 rays is used to generate a MR intensity curve to sample the tumor boundary characteristics: i) the edge of the tumor was found for each ray by finding the location at which the MR signal intensity drops below a threshold which is determined from the average MR signal intensity of the reference tissue (average intensity was calculated from an rectangular region of interest within the reference tissue of voxel size $10 \times 10$ $\times 3$ ) and its standard deviation; ii) the near boundary inside max intensity tumor coordinates (pixel location coordinates) and maximum boundary tumor signal were found by incrementing inward from the tumor edge along the ray until a maximum tumor MR signal is found within $1 \mathrm{~cm}$ of the edge; iii) the distance between tumor edge and near boundary inside tumor max signal is calculated (boundary distance); iv) the average slope between the tumor edge and tumor max signal was calculated by using the following equation:

Slope $=\{y p(i i-1$, ia $)-$ yp (ii, ia) $\}$ which is the MR signal intensity of the adjacent pixel minus the signal intensity of the current loop pixel. This change in MR signal intensity was normalized by dividing by the MR signal intensity of the reference tissue.

Where yp is MR signal intensity at the location ii along the ray, ii is incrementing factor along the ray and ia is the angle or ray number. The denominator here is 1 since each element in the $\mathrm{x}$ axis is separated by $1 \mathrm{~mm}$. The maximum slope between the tumor edge and tumor max signal is also found for each ray.

The algorithm works on one slice at a time until the entire tumor volume is covered. A set of 90 sampling rays are generated for each slice and each sampling ray has its own set of boundary characteristics which can be averaged together across the whole tumor or can be displayed as an overlay on top of the T2-weighted image. 


\section{Histopathology}

Tumor resection margin status (positive or negative) was assessed by standard histopathologic techniques by the hospital pathologist.

Figure 1. Overlay of tumor sampling rays onto MRI T2-weighted image of an example sarcoma. The MR signal along these sampling rays is used to calculate the MR quantitative slope parameters
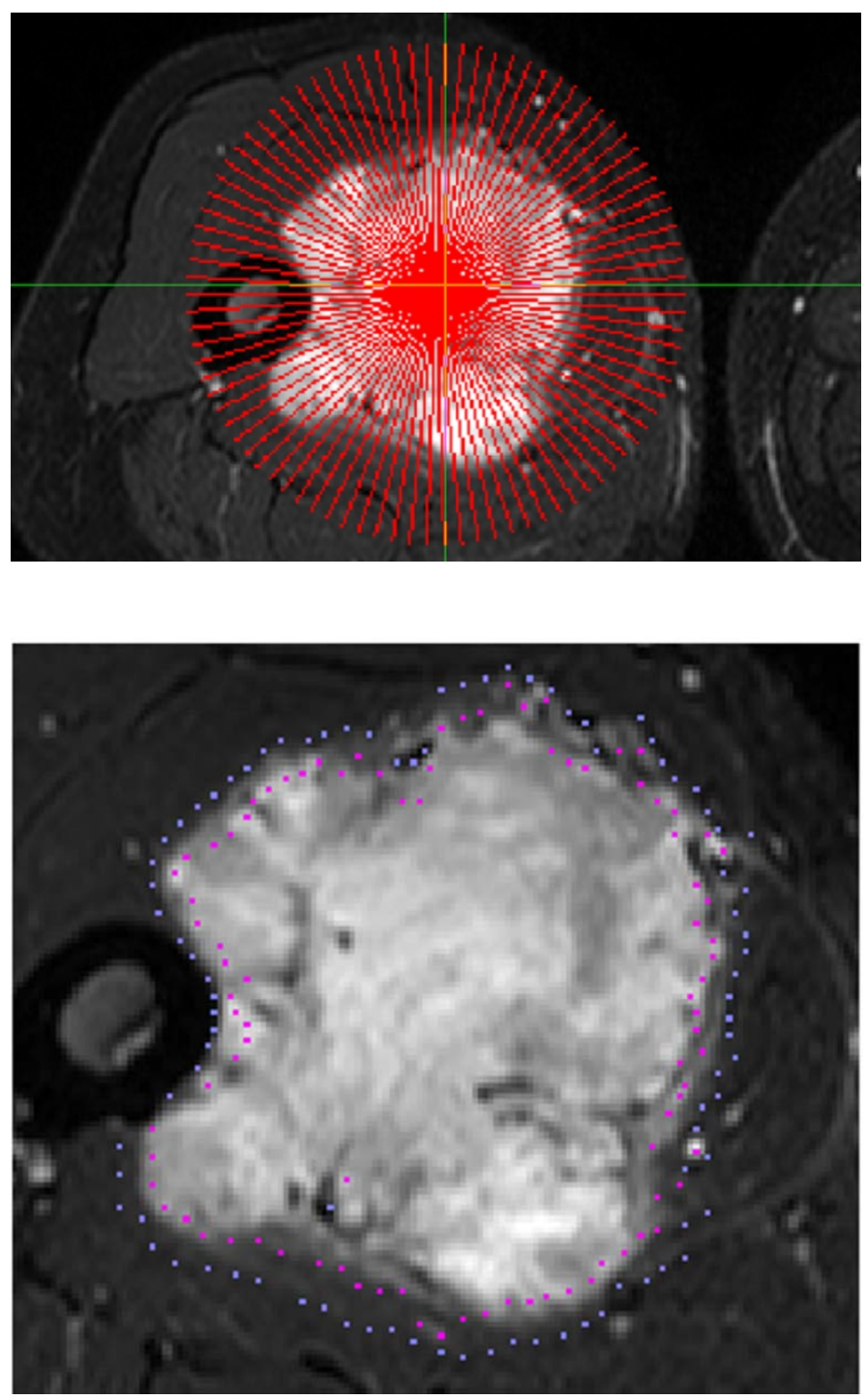

Figure 2. MRI with overlay of tumor boundary sampling parameters

In figure 2, the blue dots show the starting radial location of the boundary based on the average and standard deviation of the baseline muscle signal along the sampling rays. The pink dots show the part of the tumor where there is maximum MRI signal intensity within $1 \mathrm{~cm}$ of the starting location as the search algorithm moves inward toward the tumor center along the ray. This scan came from a 44 year old female diagnosed with synovial sarcoma in the leg.

In figure 3, the parts of the curve are labeled to show the reference signal outside of tumor, the peak tumor MR image signal near the tumor boundary, and the rapidly changing tumor MR image signal used to calculate the boundary slope.

In figure 4, Blue identifies the MR slope parameter for both negative (-) and positive (+) histopathological margin status. Yellow identifies the MR boundary distance parameter. Red identifies the maximum slope parameter and purple identifies the MR signal boundary parameter. Significant differences between negative and positive margin status were found in the MR slope (blue), distance parameter (yellow), and signal (purple). 
Figure 3. Plot of MRI intensity as a function of distance along a sampling tumor ray

Figure 4. Plot of tumor margin status versus rank of each of the four MRI parameters

Note. For each box on this plot: the thick black line in the middle of the box shows the median for that group; the box is draw between the quartiles; and the dotted lines extend to the minimum and maximum values for that group.

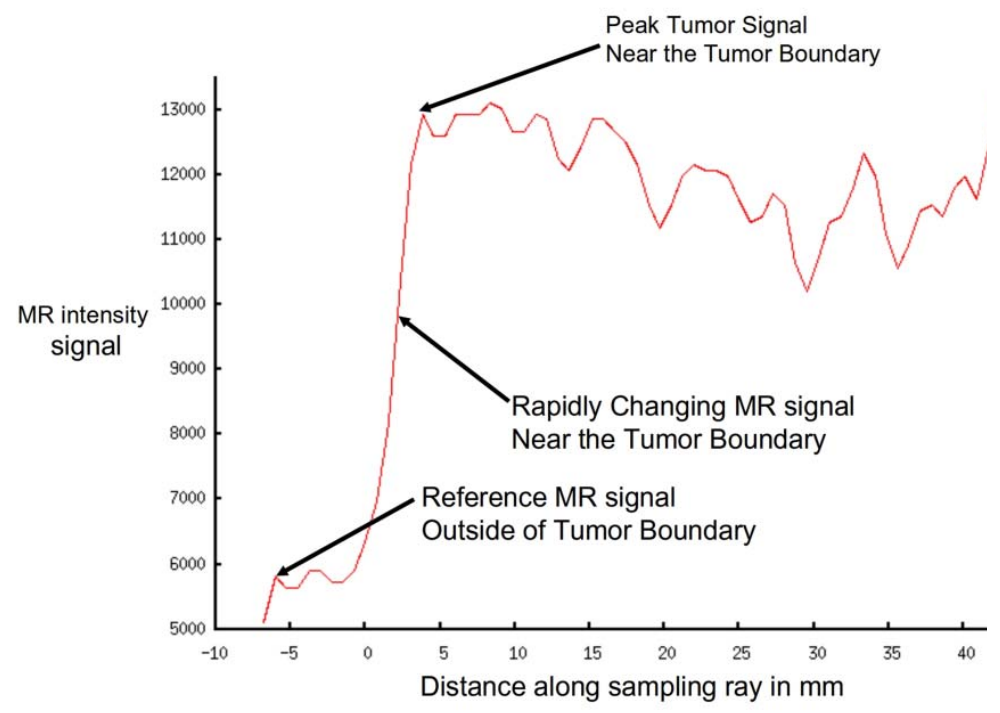

Factors Influencing Margin Status

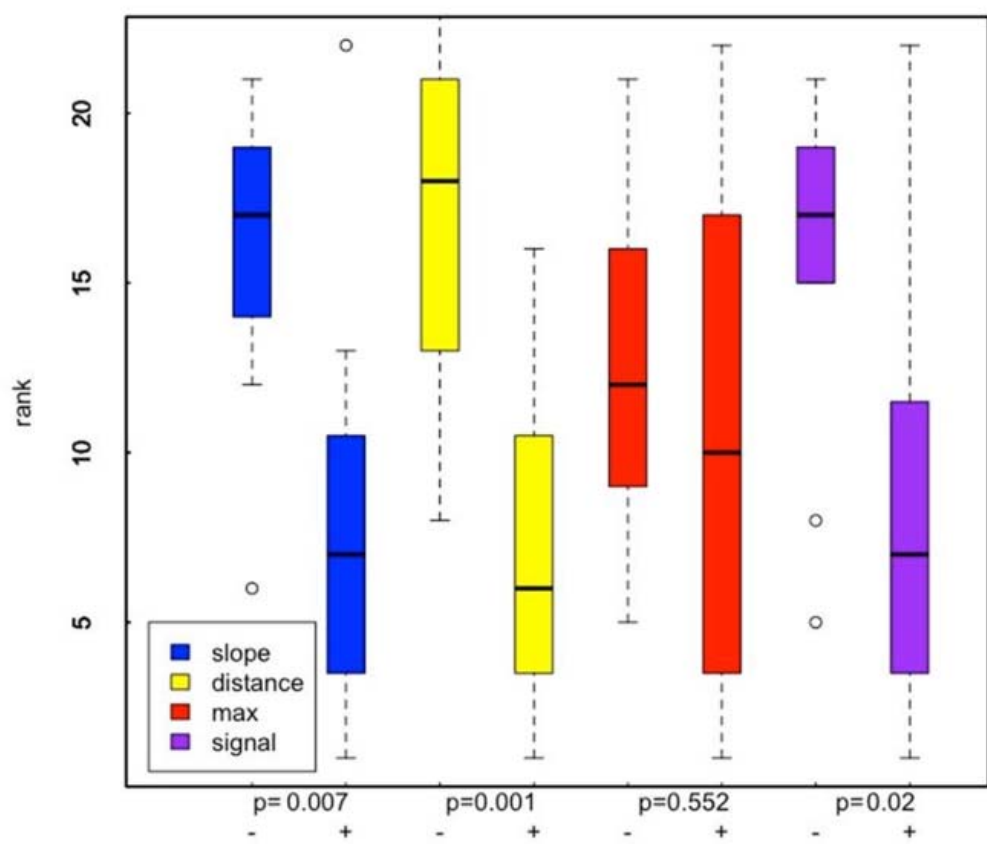

Tumor Margin Status

\section{Data analysis}

A non-parametric rank test was used to statistically test the ability of the new MR tumor boundary parameters to differentiate positive from negative margins. The individual values of the MR tumor boundary parameters were each ranked and a plot (shown in the 
results section Figure 4) was generated to compare the ranks of cases with positive margins versus those with negative ones. The $p$ values are based on the (non-parametric) rank test. In small sample situations where the assumption of normal samples cannot be relied upon, the non-parametric method is preferred over the 2-sample $t$-test in this application.

Table 1. MRI Tumor boundary characteristics and Pathology from 20 subjects

\begin{tabular}{|c|c|c|c|c|c|c|c|c|c|}
\hline $\begin{array}{l}\text { Case } \\
\text { no. }\end{array}$ & $\begin{array}{l}\text { Slope } \\
\text { (nMRI/mm) }\end{array}$ & $\begin{array}{l}\text { Slopemx } \\
\text { (nMRI/mm) }\end{array}$ & $\begin{array}{l}\text { Distance } \\
(\mathrm{mm})\end{array}$ & $\begin{array}{l}\text { Tumor } \\
\text { signal } \\
\text { (nMRI) }\end{array}$ & Location & $\begin{array}{l}\text { Size of tumor } \\
(\mathrm{cm})\end{array}$ & Diagnosis & Border type & $\begin{array}{l}\text { Margin } \\
\text { status }\end{array}$ \\
\hline 1 & 0.21 & 1.46 & 6.38 & 3.63 & $\begin{array}{l}\text { Rt } \\
\text { paraspinous }\end{array}$ & $12 \times 5.5$ & $\begin{array}{l}\text { Serous } \\
\text { carcinoma }\end{array}$ & infiltrative & positive \\
\hline 2 & 0.08 & 0.69 & 5.40 & 1.91 & Lt gluteus & $18 \times 17 \times 3.5$ & leiomyosarcoma & infiltrative & positive \\
\hline 3 & 0.28 & 1.50 & 8.50 & 4.31 & Rt thigh & $6.3 \times 7.2 \times 9$ & $\begin{array}{l}\text { synovial } \\
\text { sarcoma }\end{array}$ & infiltrative & negative \\
\hline 4 & 0.11 & 0.59 & 7.67 & 2.18 & Lt groin & $15 \times 5.5 \times 6$ & leiomyosarcoma & infiltrative & positive \\
\hline 5 & 0.06 & 2.24 & 5.15 & 2.99 & Rt forearm & $7.8 \times 1.8 \times 1.2$ & $\begin{array}{l}\text { Alveolar } \\
\text { rhabdomyosarc } \\
\text { oma }\end{array}$ & infiltrative & positive \\
\hline 6 & 0.19 & 1.15 & 7.84 & 3.28 & Lt shoulder & $9.2 \times 7.7 \times 16.3$ & $\begin{array}{l}\text { Pleomorphic } \\
\text { sarcoma }\end{array}$ & infiltrative & positive \\
\hline 7 & 0.27 & 1.17 & 7.91 & 4.18 & Lt thigh & $8 \times 6 \times 6$ & liposarcoma & encapsulated & marginal \\
\hline 8 & 0.05 & 0.51 & 4.95 & 1.72 & Rt gluteus & $8 \times 5 \times 5$ & leiomyosarcoma & encapsulated & positive \\
\hline 9 & 0.31 & 1.61 & 8.16 & 4.57 & Lt axilla & $9 \times 8 \times 4$ & liposarcoma & infiltrative & marginal \\
\hline 10 & 0.24 & 1.43 & 8.75 & 3.95 & Lt femur & $5.5 \times 3.0$ & Osteosarcoma & infiltrative & negative \\
\hline
\end{tabular}

(Table 1 continued on page 7)

\section{Results}

Study images were acquired from patients with bone and soft tissue sarcoma as proven by biopsy. The results of the four MRI tumor boundary parameters and histopathology parameters for 20 subjects are shown in Table 1 . Patient listed as case 1 in Table 1 was initially diagnosed as an unspecified myxoid sarcoma subtype located in the flank. On final pathologic diagnosis after resection, tumor markers showed it to be an unspecified type of serous adenocarcinoma.

In these patients, diagnostic MR images showed typical characteristics of soft tissue sarcoma, homogeneous signal intensity and noticeable borders with normal tissues. Some sarcomas showed heterogeneous signal intensity in Bone tumor masses usually with soft tissue involvement.

Figure 2 shows an example display of the tumor boundary distance parameter which changes along the edge of the tumor. The software defines the tumor boundary distance parameter as the radial distance between the blue and pink dots along each sampling ray. Figure 3 shows an example of the MR signal as a function of distance along one sampling ray. This image demonstrates boundary parameters features of slope and peak MR signal at the tumor boundary. 
We also tested the ability of the new MR tumor boundary parameters to differentiate tumor with involved (positive) and uninvolved (negative) resection margins by recording histopathologic data from the 20 patients with images analyzed and compared this data with the analyzed MR tumor boundary parameters. The plot shown in Figure 4 shows that significant differences were found in MRI tumor boundary parameters between tumors resected with positive or negative margins. Slope of the T2 signal change at the tumor/normal tissue boundary $(p=0.007)$ and boundary distance ( $p=0.001$ ) were significantly able to distinguish these important tumor characteristics.

Table 1. (Continued.)

\begin{tabular}{|c|c|c|c|c|c|c|c|c|c|}
\hline $\begin{array}{l}\text { Case } \\
\text { no. }\end{array}$ & $\begin{array}{l}\text { Slope } \\
\text { (nMRI/mm) }\end{array}$ & $\begin{array}{l}\text { Slopemx } \\
\text { (nMRI/mm) }\end{array}$ & $\begin{array}{l}\text { Distance } \\
(\mathrm{mm})\end{array}$ & $\begin{array}{l}\text { Tumor } \\
\text { signal } \\
\text { (nMRI) }\end{array}$ & Location & $\begin{array}{l}\text { Size of tumor } \\
(\mathrm{cm})\end{array}$ & Diagnosis & Border type & $\begin{array}{l}\text { Margin } \\
\text { status }\end{array}$ \\
\hline 11 & 0.20 & 0.99 & 8.72 & 3.10 & liver & $1.0 \times 0.6 \times 0.9$ & $\begin{array}{l}\text { desmoplastic } \\
\text { Round Cell }\end{array}$ & encapsulated & negative \\
\hline 12 & 0.17 & 0.98 & 7.34 & 3.43 & Rt pelvis & $12.5 \times 5.5 \times 9.5$ & Chondrosarcoma & infiltrative & positive \\
\hline 13 & 0.38 & 2.79 & 7.18 & 5.75 & Lt tibia & $8.8 \times 5.0 \times 3.9$ & Ewings & infiltrative & positive \\
\hline 14 & 0.22 & 1.31 & 7.54 & 3.74 & Lt thigh & $12.9 \times 7.3 \times 5.8$ & $\begin{array}{l}\text { Pleomorphic } \\
\text { sarcoma }\end{array}$ & infiltrative & negative \\
\hline 15 & 0.37 & 1.09 & 8.74 & 4.98 & Lt gluteus & $8 \times 5.5 \times 5.2$ & myxofibrosarcoma & infiltrative & negative \\
\hline 16 & 0.32 & 2.39 & 6.99 & 5.70 & Rt knee & $9 \times 7 \times 4$ & synovial sarcoma & encapsulated & negative \\
\hline 18 & 0.20 & 2.15 & 7.02 & 3.74 & Lt knee & $2.4 \times 1.8 \times 2.0$ & $\begin{array}{l}\text { Pleomorphic } \\
\text { sarcoma }\end{array}$ & infiltrative & positive \\
\hline 19 & 0.17 & 1.44 & 6.23 & 3.08 & Rt thigh & $16 \times 15.5 \times 14$ & $\begin{array}{l}\text { Spindle cell } \\
\text { sarcoma }\end{array}$ & encapsulated & positive \\
\hline 20 & 0.08 & 0.77 & 6.41 & 2.33 & Rt thigh & $10.5 \times 6.5$ & myofibrosarcoma & infiltrative & positive \\
\hline
\end{tabular}

Note. Marginal refers to a margin status where the tumor approaches to within 1-2 $\mathrm{mm}$ of the resection margin. Slope and slopemx (maximum slope) parameters are in units of change in normalized MR signal intensity (nMRI) per mm. Distance parameter is in mm. Tumor signal refers to the peak T2-weighted MR signal intensity within $1 \mathrm{~cm}$ of the tumor boundary which has been normalized to the reference tissue signal (tumor signal divided by the reference signal). This peak MR tumor signal is found using the probing rays shown in Figure 1.

*This myxoid tumor in the flank was initially diagnosed as sarcoma. On final pathologic diagnosis after resection, tumor markers showed it to be an unspecified type of serous adenocarcinoma.

\section{Discussion}

In this study, we developed analytical methods to characterize the tumor boundary using the signal from T2-weighted MRI images from patients with sarcoma. T2-weighted MRI was chosen because of the large difference in water mobility characteristics (with its associated difference in T2 relaxation time) between sarcoma and normal surrounding tissue. Our preliminary data shows that the algorithm we developed can be applied to the entire tumor volume in a clinical MRI scan. From this analysis, the slope of the T2-weighted intensity of the tumor signal was plotted as a function of ray angle in a test data set of sarcoma tumors. The border MR parameters are based on a software technique which uses radial sampling rays stemming from a middle point inside the tumor. Each sampling ray contains the MR intensity values as a function of distance along that ray which includes both tumor and surrounding tissue near the border. We have determined that the slope of change in the image intensity at the tumor/normal tissue boundary is one of the most significant measurements to be extracted. This measure can locate edematous regions that may contain tumor infiltrate, inflammatory infiltrates and changes in connective tissue compared to normal surrounding muscle background. In this mixed group of soft-tissue and bony sarcomas, there was a large variability in these border parameters between subjects. This is likely due to the non-similarities in the biological behavior in these tumors. Sarcomas have different pathologies 
based on differing cellular growth rates, vascularity, necrosis, ground substance, and fluid collections. Histologic examination of these tumors has long shown that these tumor features also imply aggressive behavior.

The four tumor boundary characteristics described above have possible biological/behavioral implications. The slope boundary parameter is determined from average change in the MRI signal intensity as a function of distance at the tumor boundary and is related to the biological/biophysical properties of tumor water versus normal tissue near the tumor boundary. In other words, the T2-weighted MRI intensity changes as a function of distance along the sampling ray which traverses space within the tumor to outside the tumor. This change in MRI intensity was used to calculate a slope used in the slope boundary parameter. Each tumor shown in Table 1 has different set of MR tumor boundary parameters which can be used to help in surgical planning for a procedure that minimizes risk for tumor recurrence and in many cases preserves limb function. The ability to distinguish between positive and negative tumor-involved margins by this image analysis is demonstrated in this test data set. This boundary analysis method which is different than simple edge detection reports on the tumor-normal tissue interface.

\section{Acknowledgements}

This project was funded by the National Institute of Heath/National Cancer Institute grant number R01CA065537-14 (Principal Investigator -Dr. Janet Eary).

\section{Conflict of interest statement}

We declare that we have no conflict of interest.

\section{References}

[1] Allen SD, Moskovic EC, Fisher C, et al. Adult rhabdomyosarcoma: cross-sectional imaging findings including histopathologic correlation. AJR Am J Roentgenol. 2007;189 (2):371-77. PMid: 17646463. http://dx.doi.org/10.2214/AJR.07.2065

[2] Barile A, Zugaro L, Catalucci A, et al. Soft tissue liposarcoma: histological subtypes, MRI and CT findings. Radiol Med. 2002;104(3):140-49.

[3] Collins MS, Koyama T, Swee RG, et al. Clear cell chondrosarcoma: radiographic, computed tomographic, and magnetic resonance findings in 34 patients with pathologic correlation. Skeletal Radiol. 2003;32(12):687-94. PMid: 14530882. http://dx.doi.org/10.1007/s00256-003-0668-3

[4] Dim DC, Cooley LD, Miranda RN. Clear cell sarcoma of tendons and aponeuroses: a review. Arch Pathol Lab Med. 2007;131 (1):152-56. PMid: 17227118.

[5] Donmez FY, Tuzun U, Basaran C, et al. MRI findings in parosteal osteosarcoma: correlation with histopathology. Diagn Interv Radiol. 2008;14(3):142-52. PMid: 18814136.

[6] Elias DA, White LM, Simpson DJ, et al. Osseous invasion by soft-tissue sarcoma: assessment with MR Imaging. Radiology. 2003;229(1):145-52. PMid: 14519874. http://dx.doi.org/10.1148/radiol.2291020377

[7] Fernebro J, Wiklund M, Jonsson K, et al. Focus on the tumor periphery in MRI evaluation of soft tissue sarcoma: infiltrative growth signifies poor prognosis. Sarcoma. 2006;21251.

[8] Furukawa R, Akahane M, Yamada H, et al. Endometrial stromal sarcoma located in the myometrium with a low-intensity rim on T2-weighted images: report of three cases and literature review. J Magn Reson Imaging. 2010;31(4):975-79. PMid: 20373443. http://dx.doi.org/10.1002/jmri.22126

[9] Hartman RP, Sundaram M, Okuno SH, et al. Effect of granulocyte-stimulating factors on marrow of adult patients with musculoskeletal malignancies: incidence and MRI findings. AJR Am J Roentgenol. 2004;183(3):645-53. PMid: 15333351.

[10] Ishikawa M, Ishizuka O, Nakayama T, et al. Alveolar soft-part sarcoma of the retroperitoneum. Int J Urol 2006;13(10):1355-57.

[11] Kumagai K, Tomita M, Nozaki Y, et al. MRI findings of an inflammatory variant of well-differentiated liposarcoma. Skeletal Radiol. 2010;39(5):491-94. PMid: 20054537. http://dx.doi.org/10.1007/s00256-009-0852-1

[12] Li WY, Brock P, Saunders DE. Imaging characteristics of primary cranial Ewing sarcoma. Pediatr Radiol. 2005;35(6):612-8. PMid: 15815902. http://dx.doi.org/10.1007/s00247-005-1438-2

[13] Lin PP, Pino ED, Normand AN, et al. Periosteal margin in soft-tissue sarcoma. Cancer. 2007;109(3):598-602. PMid: 17183556. http://dx.doi.org/10.1002/cncr.22429 
[14] Liu QY, Li HG, Chen JY, et al. [Correlation of MRI features to histopathologic grade of soft tissue sarcoma]. Ai Zheng. 2008;27(8):856-60. PMid: 18710621.

[15] Miyake M, Tateishi U, Maeda T, et al. CT and MRI features of low-grade fibromyxoid sarcoma in the shoulder of a pediatric patient. Radiat Med. 2006;24(7):511-14. PMid: 17058145. http://dx.doi.org/10.1007/s11604-006-0057-7

[16] Murphey MD, Jelinek JS, Temple HT, et al. Imaging of periosteal osteosarcoma: radiologic-pathologic comparison. Radiology. 2004;233(1):129-38. PMid: 15333772. http://dx.doi.org/10.1148/radiol.2331030326

[17] Murphey MD, wan Jaovisidha S, Temple HT, et al. Telangiectatic osteosarcoma: radiologic-pathologic comparison. Radiology.2003;229(2):545-53. PMid: 14512511. http://dx.doi.org/10.1148/radiol.2292021130

[18] Namimoto T, Yamashita Y, Awai K, et al. Combined use of T2-weighted and diffusion-weighted 3-T MR imaging for differentiating uterine sarcomas from benign leiomyomas. Eur Radiol. 2009;19(11):2756-64. PMid: 19504102. http://dx.doi.org/10.1007/s00330-009-1471-x

[19] Peersman B, Vanhoenacker FM, Heyman S, et al. Ewing's sarcoma: imaging features. Jbr-Btr. 2007;90(5):368-76. PMid: 18085191.

[20] Pilavaki M, Drevelegas A, Nenopoulou H, et al. Foci of decreased signal on T2-weighted MR images in leiomyosarcomas of soft tissue: correlation between MR and histological findings. Eur J Radiol. 2004;51(3):279-85. PMid: 15294338. http://dx.doi.org/10.1016/j.ejrad.2003.10.008

[21] Tanaka YO, Nishida M, Tsunoda H, et al. Smooth muscle tumors of uncertain malignant potential and leiomyosarcomas of the uterus: MR findings. J Magn Reson Imaging. 2004;20(6):998-1007. PMid:15558559 http://dx.doi.org/10.1002/jmri.20207

[22] Tateishi U, Hasegawa T, Nojima T, et al. MRI features of extraskeletal myxoid chondrosarcoma. Skeletal Radiol. 2006;35(1):2733. PMid: 16220270. http://dx.doi.org/10.1007/s00256-005-0021-0

[23] Varma DG. Imaging of soft-tissue sarcomas. Curr Oncol Rep. 2000;2(6):487-90. PMid: 11122882. http://dx.doi.org/10.1007/s11912-000-0100-2 